\section{Impact of new long-stay patients on Irish psychiatric inpatient services}

Dear Editor, Re: An audit of new long-stay patients in Irish psychiatric inpatient services, by Daly A and Walsh D, of the Mental Health research Unit of the Health Research Board, Dublin; published in the Ir J Psych Med 2009; 26(3): 134-139. Many thanks for the authors for such an interesting and relevant article. The author wishes to point out some earlier references, which Daly and Walsh might have missed. Thompson et al have reported the psychiatric admission patterns for England in the year 2000. ${ }^{1}$ Dixit A, compared this English study data with the Health Research Board (HRB), Dublin's annual report 2000..$^{2,3}$ One of the implications of Dixit's study was to demonstrate the need for further study and audit in new long-stay psychiatric inpatients.

The author wishes to point out that for the calculations of the economic cost of illness studies, like study of schizophrenia in Ireland by Behan et al, it is important to report all the inpatient days (bed-days), in the annual reports of HRB. The HRB has consistently not included the bed usage data on patients with stay over one year, as it grossly distorts the calculations on the length of stay. ${ }^{4}$ The author wishes to argue about ways to overcome this problem, and is looking for the experts' opinion on the methodology used.

Table 2 details length of stay in new long-stay patients $(n=460)$, in Daly and Walsh's study, suggests that the median length of stay in this group is 33 months $(\sim 1000$ days)(midpoint of 31-36 months). ${ }^{5}$ If this is averaged out for the period of five years, the value comes to $\sim 200$ days per annum.

Thus $200 \times 460=92,000$ inpatient days need to be added to the number of total inpatient days $(547,770)$ for the year 2006 , corrected total being; 639,770 inpatient days. After this correction, we can calculate the impacts of two important patient groups. The HRB report 2006, reports patients with stay over three months and under one year, accounted for 169,357 inpatient days, with average length of stay 158 days, and median length of stay 129 days. This accounts for $\sim 26.5 \%$ of total inpatient days, while new long-stay patients (patients with stay over one year and under five years), account for $\sim 14.4 \%$ total annual inpatient days. Thus, in spite of the recommendations and policies, slightly over $40 \%$ of total inpatient days are due to , $7 \%$ of total psychiatric inpatients staying at the unit over three months, giving many acute units the feel of long-stay psychiatric wards. Similar observation is made by Lelliot et al in their national level audit of new long stay patients in England. ${ }^{6}$

This letter aims to generate interest, create discussion and help further cost studies on mental illnesses, which are sparse in Ireland. ${ }^{7}$

\section{Ajay Dixit MD, DPM, \\ Registrar in Psychiatry, Mercy University Hospital, Cork}

References

1. Thompson A, Shaw M, Harrison $\mathrm{G}$ et al 2004. Patterns of hospital admission for adult Psychiatric illness in England: analysis of Hospital episode Statistics data'. $\mathrm{Br} J$ of Psych 2004; 185: 334-341.

2. Daly A, Walsh D, 'Activities of the Irish psychiatric services- 2000'. Health Research Board, Dublin. pp 1 to $5,22,23,24,125$ (Tables 2.1, 2.2, 2.3, 4.2, appendix 2).

3. Dixit A. Patterns of hospital admission for adult psychiatric illness in England and Ireland: a comparative study. Irish Psychiatrist, vol9, Issue1, Spring 2008 (Feb-Mar)

4. Daly A, Walsh D, Moran R. Activities of the Irish psychiatric services-2006.
Table2.12,pp47.

5. Daly A, Walsh D. An audit of new long-stay patients in Irish psychiatric inpatient services'. Ir J Psych Med 2009; 26(3):134-139.

6. Lelliot $P$, Wing J. A National Audit of new long-stay psychiatric inpatients: impact on services.Br J Psych 1994; 165:160-169.

7. Behan $C$, Kennelly B, O'Callaghan E. The economic cost of schizophrenia in Ireland: a cost of illness study. Ir J Psych Med 2008; 25(3): 80-87.

\section{New long-stay patients}

Dear Editor, Dr Dixit's letter raises interesting points concerning inpatient days and the cost of illness. However, a number of points should be noted. The letter mentions that it is important to report the inpatient days spent in hospital of all discharged patients in the annual reports of the HRB. As the HRB Activities of Irish Psychiatric Units and Hospitals reports point out, those with a length of stay of one year or more are excluded from the analysis of inpatient days as they distort the number of inpatient days considerably, and it is further noted that $2 \%$ of discharges are thus excluded. Were they to be included a miniscule percentage of discharges would contribute overwhelmingly to the totality of inpatient days reported because a very small number of patients discharged after possibly 10-25 years in hospital, would enormously inflate the inpatient days reported. For example, in 2008, there were 39 discharges for patients with a length of stay of 25 years or more, accounting for $0.2 \%$ of all discharges in 2008 and $32 \%$ of inpatient days (Table 1). ${ }^{1}$ This group had an average length of stay of 13,902 days and median 13,066 days. Half of all inpatient days on discharge were accounted for by those with a length of stay of 10 years or more and yet these patients accounted for just $0.5 \%$ of all discharges. When all discharges are considered, there were $1,671,411$ inpatient days; however the $2 \%$ of discharges excluded from the HRB report accounted for $1,161,566$ of these inpatient days, with $98 \%$ accounting for 509,845 inpatient days.

When inpatient days by hospital type are examined for 2008 it can be seen (Table 2) ${ }^{1}$ that over $73 \%$ of inpatient days on discharge are accounted for by psychiatric hospital discharges (as distinct from general hospital units) which leads us back to our primary concern in the paper Dixit refers to, ie., whether the outcome of our follow-up of the long stay patients one year later would facilitate the closure of the older psychiatric hospitals given that $86 \%$ of these patients resided in these psychiatric hospitals. Unfortunately the results were not encouraging in this regard. Hence, this would lead us to conclude that a very small proportion of long-stay patients in psychiatric hospitals are contributing to a huge amount of the total number of inpatient days and impeding the closure of these hospitals in line with policy.

In addition, Dr Dixit's letter mentions that 'Thus in-spite of the recommendations and policies slightly over $40 \%$ of total inpatient days are due to, $\sim 7 \%$ of total psychiatric inpatients staying at the unit over three months, giving many acute units the feel of long-stay psychiatric ward'. However our study shows that only a minority of long-stay discharges were from general hospital units. Indeed the HRB psychiatric inpatient census in 2006 reported that of 785 patients resident in general hospital psychiatric units on $31 / 03 / 06$, only $32(4 \%)$ had been in hospital for more than one year.

Antoinette Daly, Dermot Walsh, The Health Research Board,

Dublin

References

1. Daly A and Walsh D (2009). Activities of Irish Psychiatric Units and Hospitals 2008. 